\title{
Ácido giberélico na indução e qualidade do florescimento de orquídea Phalaenopsis 'White Dream'(1)
}

\author{
JEAN CARLOS CARDOSO(2); ELIZABETH ORIKA ONO(3); JOÃO DOMINGOS RODRIGUES ${ }^{(3)}$
}

\begin{abstract}
RESUMO
No cultivo de flores, o controle da floração é fator fundamental para comercialização rápida e com redução de custos. Foi avaliada a utilização do ácido giberélico (GA3) na indução floral e qualidade do florescimento de plantas adultas de Phalaenopsis híbrido. Foram testadas 5 concentrações de GA3 de 0, 125, 250, 500 e $1000 \mathrm{mg} \mathrm{L}-1$ em 2 ou 4 pulverizações com intervalos de 7 dias, feitas via foliar nos meses de novembro e dezembro. Resultados promissores para a indução do florescimento ocorreram com a concentração de $125 \mathrm{mg} \mathrm{L}-1$ de GA3, pulverizado por 2 vezes em plantas de Phalaenopsis, com $83 \%$ das plantas floridas. O número de flores aumentou com o incremento das doses de GA3 até a concentração de 1.000 mg L-1 em 2 pulverizações, sem diminuição da qualidade das flores até a concentração de 500mg L-1. Já o uso de 4 aplicações de GA3 e o consequente aumento das concentrações de aplicação do regulador vegetal nas plantas ocasionaram diminuição da qualidade das inflorescências e flores obtidas.

Palavras-chave: Phalaenopsis, planta ornamental, regulador vegetal, flores.
\end{abstract}

\section{ABSTRACT}

Gibberellic Acid (GA) on flowering induction and quality of Phalaenopsis orchid

\begin{abstract}
The control of flowering is essential in the cultivation of flowers to the rapid commercialization and cost reduction. We evaluated the use of Gibberellic Acid (GA3) on floral induction and quality of flowering of adult plants of Phalaenopsis hybrid. It was test five concentrations of GA3: 0, 125, 250, 500 and $1.000 \mathrm{mg} \mathrm{L}-1$ applied twice or four times with seven days of interval. This was made by foliar pulverization in the months of November and December. Promising results for induction of flowering happened at a concentration of $125 \mathrm{mg} \mathrm{L}-1 \mathrm{GA} 3$, applied for twice in Phalaenopsis plants, and with $83 \%$ of flowering plants. The number of flowers increased with increasing doses of GA3, until the concentration of 1.000 mg L-1 applied by twice, and without lost of flowers quality until 500mg L-1. The use of four applications of GA3 and the consequent elevation of concentration of the growth regulator in treated plants, caused reduction of inflorescences and flowers quality.
\end{abstract}

Keywords: Phalaenopsis, ornamental plant, growth regulators, flowers.

\section{INTRODUÇÃO}

O mercado interno de flores no Brasil está em plena ascendência, mas o Brasil vem apresentando quedas na balança comercial de flores e plantas ornamentais nos últimos anos (JUNQUEIRA E PEETZ, 2010). As orquídeas compreendem uma família de mais de 25 mil espécies espalhadas por todo o mundo e mais de 100.000 híbridos produzidos naturalmente ou por cruzamentos controlados (CARDOSO et al., 2005). Entre as variedades requisitadas pelo mercado, estão os gêneros Cattleya, Phalaenopsis, Oncidium, Cymbidium, Dendrobium e seus inúmeros híbridos. O gênero Phalaenopsis tem se destacado como planta de vaso mais comercializada no Veilling Holambra e tem atraído atenção especial na cadeia de produção e comercialização (CEASA, 2012; VEILLING, 2012).

$\mathrm{O}$ crescimento da demanda de tecnologias aplicadas ao cultivo de Phalaenopsis é consequência dessa rápida expansão do mercado de flores no Brasil, sendo o controle do florescimento fator primordial dentro da cadeia de produção. Existem várias hipóteses para explicar os fatores que influenciam o florescimento em plantas, mas pouco se conhece quanto ao estímulo da floração, sendo que na maioria das espécies a temperatura, o fotoperíodo e condições de estresse são direta ou indiretamente responsáveis pela indução do florescimento. Atualmente, a descoberta do gene Ft em plantas tem dado suporte e restaurado a hipótese do florígeno (TAIZ e ZEIGER, 2008; KERBAUY, 2008).

Algumas giberelinas sintéticas, quando aplicadas exogenamente, promovem a indução de floração em plantas de dias longos sob condições de dias curtos e em plantas que necessitam de um período de baixas temperaturas ou vernalização para florescer (CID, 2000; DAVIES, 1995).

As espécies e híbridos de Phalaenopsis necessitam de um período de 3 a 5 semanas de exposição à queda de temperatura, de $25^{\circ} \mathrm{C}$ para $15^{\circ} \mathrm{C}$, para iniciar a emissão das inflorescências, mas a aplicação externa de $\mathrm{GA}_{3}$ em Phalaenopsis em épocas de altas temperaturas para induzir a emissão de inflorescências não resultou na obtenção de flores (WANG, 1995). Porém, foi possível induzir o florescimento em Phalaenopsis Leda com a aplicação de

\footnotetext{
(1) Recebido em 17/06/2010 e aceito para publicação em 30/07/2012.

(2) Departamento de Desenvolvimento Rural, CCA / UFSCar, Rod. Anhanguera, km 174, Araras, SP, jeancardosoctv@gmail.com;

${ }^{(3)}$ Departamento de Botânica - IBB - Unesp de Botucatu, SP. eoono@ibb.unesp.br.
} 
$\mathrm{GA}_{3}$, mesmo em condições de altas temperaturas, que são desfavoráveis à indução (CHEN et al. 1997).

O objetivo do presente trabalho foi avaliar a aplicação de diferentes doses e pulverizações com $\mathrm{GA}_{3}$ na indução do florescimento e qualidade das flores de orquídeas Phalaenopsis 'White Dream' de flores brancas, em condições de altas temperaturas, desfavoráveis ao florescimento natural destas orquídeas.

\section{MATERIAL E MÉTODOS}

O experimento foi conduzido no município de Pompeia, SP, Brasil, latitude $22^{\circ} 06^{\prime} 29^{\prime \prime}$, longitude 50¹0’36”, e teve duração de, aproximadamente, 6 meses.

Foram utilizadas, como material vegetal, plantas adultas híbridas de Phalaenopsis de coloração branca com aproximadamente três anos de cultivo e que já haviam florescido ao menos uma vez em seu ciclo. As mudas foram provenientes de laboratório de cultura de tecidos, sendo plantas originárias de sementes de um mesmo cruzamento, Phalaenopsis 'White Dream' x 'White Dream'.

A escolha das plantas para o experimento foi feita na época de floração anterior à aplicação do $\mathrm{GA}_{3}$, escolhendose plantas com floração uniforme e qualidade para o comércio de flores, como haste longa e mínimo de 9 flores por haste, com o objetivo de uniformizar o lote do experimento quanto aos aspectos genéticos da floração. As plantas selecionadas foram cultivadas em estufas agrícolas com sombreamento obtido pela combinação de sombrite preto $70 \%$ mais Aluminet ${ }^{\circledR} 30 \%$, intercalados em duas camadas, irrigação feita quatro vezes por semana, com aproximadamente $200 \mathrm{ml}$ de água por planta por irrigação, acrescida de uma fertirrigação semanal, com solução $1 \mathrm{~g}$ $\mathrm{L}^{-1}$, da formulação 15-15-20, mantendo-se estas condições constantes durante todo o período experimental.

Como tratamentos, foram utilizadas cinco concentrações de $\mathrm{GA}_{3}$ de $0,125,250,500$ e $1.000 \mathrm{mg} \mathrm{L}^{-1}$ em duas ou quatro pulverizações, sendo o intervalo entre as aplicações de sete dias, totalizando dez tratamentos dispostos em blocos ao acaso, em esquema fatorial $5 \times 2$ (cinco concentrações e duas frequências de aplicação). No experimento, foram utilizadas três repetições com duas plantas cada, totalizando seis plantas por tratamento.

O produto utilizado foi o $\mathrm{GA}_{3}$ com mínimo de $95 \%$ de pureza. O produto foi diluído em $4 \mathrm{~mL}$ de álcool hidratado $92,8^{\circ} \mathrm{GL}$, tendo sido adicionado a esta solução 1 mL de Tween 20® (Monolaurato de Sorbitan Etoxilado - surfatante não iônico) por litro de solução, antes de se completar a solução com água. As testemunhas foram tratadas com água mais Tween $20 \AA$ a $0,1 \%$.

As pulverizações foram feitas nos meses de novembro e dezembro, entre 7 e 8:00h da manhã, período em que a umidade relativa do ar era alta, favorecendo a absorção do produto. Para a pulverização foliar, foi utilizado pulverizador costal de 20 L marca Jacto ${ }^{\circledR}$ acoplado com bico tipo cônico X2. No momento da aplicação, as plantas que receberam a pulverização foram separadas das demais para evitar contaminação com resíduos. As soluções foram aplicadas direcionalmente à face adaxial das folhas, utilizando-se cerca de $50 \mathrm{~mL}$ da solução por planta, notando-se escorrimento de parte do produto para as raízes.
Para a avaliação do efeito do $\mathrm{GA}_{3}$ no florescimento de Phalaenopsis, foram avaliados a taxa de florescimento e o número de inflorescências e de flores obtidas nos respectivos tratamentos. Para avaliação da qualidade da floração, foram mensurados os diâmetros das flores e das pétalas com uma régua milimetrada. As medições foram feitas na segunda e terceira flores a partir da sequência de antese das flores, cerca de 14 dias após sua antese, obtendo-se as médias do diâmetro das flores e das pétalas. Também foi avaliada a presença de defeitos ocasionados pelos tratamentos, sendo as flores classificadas com a nota 3 aquelas sem defeitos e boa qualidade para a comercialização, nota 2, aquelas apresentando defeitos leves e toleráveis no comércio e nota 1, aquelas com defeitos graves que inviabilizariamm a comercialização do Phalaenopsis.

Os resultados foram submetidos à análise de variância, sendo as médias de taxa de florescimento, diâmetro de flores e pétalas e qualidade de flores comparadas pelo teste de Duncan a $5 \%$ de probabilidade e à análise de regressão para efeitos das doses de ácido giberélico, comprimento de inflorescência e número de flores.

\section{RESULTADOS E DISCUSSÃO}

O aumento na porcentagem de plantas floridas de Phalaenopsis 'White Dream' com as concentrações utilizadas de $\mathrm{GA}_{3}$ em relação às plantas pulverizadas com água está relacionado a diferentes fatores que podem levar a indução do florescimento. $\mathrm{O} \mathrm{GA}_{3}$ a $125 \mathrm{mg} \mathrm{L}^{-1}$ aplicado duas vezes nas plantas induziu $83,0 \%$ das plantas ao florescimneto em comparação a $17,0 \%$ das plantas pulverizadas com água (Tabela 1). $\mathrm{O}$ aumento no número ou concentração das aplicações de $\mathrm{GA}_{3}$ diminuiu a porcentagem de plantas floridas, com média entre 30 e $50 \%$ por tratamento, porém todas acima da taxa de florescimento daquelas pulverizadas com água. Não houve interação entre os fatores concentração de $\mathrm{GA}_{3}$ e número de pulverizações.

Em Arabidopsis thaliana, as GAs promovem e controlam o florescimento pela ativação do gene promotor LEAFY (BLÁSQUEZ et al., 1998). As GAs estão associadas à indução do florescimento em plantas de dias longos que requerem vernalização para florescer (MUTASAGÖTTGENS e HEDDEN, 2009). Tanto a ocorrência de baixas temperaturas, quanto as condições de dias longos estão associadas ao aumento na biossíntese interna e à indução do florescimento pelas GAs. Estas condições, por sua vez, ativam a enzima $\alpha$-amilase, resultando no aumento da relação $\mathrm{C} / \mathrm{N}$ nas folhas (TAIZ e ZEIGER, 2008). O $\mathrm{GA}_{3}$ também estimulou o florescimento e a atividade fotossintética em Zantedeschia 'Black Magic', sendo esse outro fator associado ao aumento da relação $\mathrm{C} / \mathrm{N}$ pelas GAs (KOZLOWSKA et al., 2007).

KATAOKA et al. (2004) observaram aumento do teor de sacarose nas folhas de plantas de Phalaenopsis em préflorescimento, tendo o uso de temperaturas altas reduzido tanto o teor de sacarose quanto a taxa de florescimento desta orquídea.

As espécies e híbridos de Phalaenopsis necessitam de um período de 3 a 5 semanas de exposição à queda de temperatura de $25^{\circ} \mathrm{C}$ para $15^{\circ} \mathrm{C}$ para iniciar a emissão das inflorescências. A aplicação externa de GA3 ou uma 
mistura de benziladenina e $\mathrm{GA}_{4+7}$ em Phalaenopsis em condições de verão (altas temperaturas) não resultou na indução da floração, pois não houve formação de botões florais (WANG, 1995). No entanto, plantas de Phalaenopsis amabilis, espécie que deu origem a todos os híbridos brancos comercializados atualmente, foram induzidas a florescer em condições de altas temperaturas $\left(30^{\circ} \mathrm{C} \mathrm{dia} / 25^{\circ} \mathrm{C}\right.$ noite) com a aplicação de $\mathrm{GA}_{3}$ (CHEN et al., 1994).

O florescimento e em especial a fase de indução é um mecanismo complexo em plantas, envolvendo diferentes fatores atuando em conjunto para a indução floral. A grande variedade de espécies utilizadas em cruzamentos na obtenção de híbridos comerciais de Phalaenopsis, associada às condições fisiológicas das plantas e à tecnologia de aplicação dos reguladores vegetais, explica, em parte, o sucesso ou insucesso da indução da floração pela aplicação do $\mathrm{GA}_{3}$.

$\mathrm{O}$ número de inflorescências não variou com os tratamentos, mantendo-se em média uma inflorescência por planta em todos os tratamentos. O número de inflorescências parece ser um fator determinado geneticamente em Phalaenopsis, já que plantas que emitem mais de uma inflorescência por floração repetem este mesmo comportamento ao longo dos ciclos de floração (dados não publicados). Como as plantas selecionadas apresentavam uma única inflorescência, este número foi mantido e não houve influência do $\mathrm{GA}_{3}$.

Nos tratamentos com duas pulverizações de $\mathrm{GA}_{3}$, o comprimento das inflorescências aumentou até a concentração de $500 \mathrm{mg} \mathrm{L}^{-1}$ com posterior redução na concentração de $1.000 \mathrm{mg} \mathrm{L}^{-1}$. Com quatro pulverizações de $\mathrm{GA}_{3}$, o maior comprimento de inflorescência foi obtido na concentração de $250 \mathrm{mg} \mathrm{L}^{-1}$, com redução do comprimento em concentrações maiores (Figura 1A). Com duas pulverizações de $\mathrm{GA}_{3}$, houve acréscimo no número de flores com o aumento das concentrações de $\mathrm{GA}_{3}$; com quatro pulverizações, houve incremento no número de flores na concentração de $125 \mathrm{mg} \mathrm{L}^{-1}$ e redução gradativa com o aumento das concentrações de aplicação (Figura 1B). No entanto, não foram observados os mesmos tipos de correlações anteriores entre o comprimento da inflorescência e o número de flores (Figuras $1 \mathrm{C}$ e 1D), já que se poderia esperar efeito indireto do $\mathrm{GA}_{3}$ sobre o aumento do comprimento das inflorescências que, consequentemente, elevaria o número de flores por inflorescência. Portanto, houve efeito direto das concentrações de $\mathrm{GA}_{3}$ na quantidade de flores obtidas por inflorescência em Phalaenopsis 'White Dream'.

Os resultados obtidos nesse experimento estão de acordo com os obtidos em outras espécies. O $\mathrm{GA}_{3}$, aplicado pela imersão na concentração de $100 \mathrm{mg} \mathrm{L}^{-1} \mathrm{em}$ colmos de Gladiolus grandiflorus 'Eurovision', acelerou o florescimento e aumentou a porcentagem de plantas floridas, comprimento de inflorescência e número de flores nesta espécie, melhorando a produtividade e a qualidade da floração (KARAGÜZEL et al., 2007). Também foi observado aumento no número de flores em Zantedeschia 'Black Magic' pela aplicação de GA (KOZLOWSKA et al., 2007). A aplicação de $\mathrm{GA}_{3}$ em morango (Fragaria $x$ ananassa) aumentou o número, o peso e a qualidade de frutos produzidos (DUARTE FILHO et al. 2004), mostrando que o efeito desse regulador vegetal na qualidade não se aplica apenas a flores.

Os hormônios vegetais são substâncias orgânicas que atuam na expressão gênica, biossíntese e ativação enzimática nas plantas (KERBAUY, 2008), e a aplicação dos reguladores vegetais em concentrações adequadas auxilia na expressão de seu potencial genético. Assim, o aumento gradativo do número de flores por planta com o aumento das concentrações de $\mathrm{GA}_{3}$ nos tratamentos com duas pulverizações mostra a expressão do potencial genético das plantas de Phalaenopsis tratadas com este regulador vegetal. Porém, doses elevadas ocasionam efeitos fitotóxicos, explicando a redução do número de flores e o aumento excessivo no comprimento das inflorescências com o uso de quatro aplicações de doses acima de $125 \mathrm{mg} \mathrm{L}^{-1}$.

Não houve diferenças para o diâmetro de flores em diferentes concentrações de $\mathrm{GA}_{3}$ quando foram utilizadas duas pulverizações. Porém, houve incremento no diâmetro de pétalas nas concentrações de 250 e $500 \mathrm{mg} \mathrm{L}^{-1}$ com manutenção da qualidade das flores. Ainda com duas pulverizações, houve leve redução no diâmetro de pétalas na concentração de $125 \mathrm{mg} \mathrm{L}^{-1}$, porém isso não prejudicou a qualidade das flores. Com quatro pulverizações de $\mathrm{GA}_{3}$, o aumento das concentrações incrementou o diâmetro das flores até a concentração de $500 \mathrm{mg} \mathrm{L}^{-1}$, porém isso não foi acompanhado pelo aumento no diâmetro das pétalas, prejudicando a qualidade das flores, que se reduziu de três para um. A perda de qualidade em concentrações mais altas deveu-se também à presença de defeitos graves, como pétalas tortas e com alterações morfológicas, o que prejudica a comercialização do produto (Tabela 2). Em Phalaenopsis, o diâmetro das flores e pétalas tem grande importância na seleção de materiais com floração de boa qualidade.

Atualmente, utilizando classificação comercial, plantas com inflorescências excessivamente curtas ou longas, poucas flores, com pequeno diâmetro ou apresentando defeitos visuais são consideradas de baixa qualidade, podendo ser comercializadas a preços menores ou mesmo impedidas de comercialização (VEILLING, 2009).

Em Phalaenopsis Leda, embora a indução do florescimento pela aplicação do $\mathrm{GA}_{3}$, as altas temperaturas na época de desenvolvimento das flores tenham ocasionado defeitos graves na qualidade das flores, os autores observaram que a aplicação de baixas concentrações de benziladenina associada ao $\mathrm{GA}_{3}$ para a indução do florescimento originou flores com a mesma qualidade daquelas que florescem naturalmente em condições de temperaturas mais baixas (CHEN et al. 1997).

O experimento permitiu desenvolver uma técnica para indução do florescimento em Phalaenopsis em condições de altas temperaturas, época desfavorável ao florescimento da espécie e em que há falta do produto no mercado, consequentemente, permitindo ao produtor obter preços melhores, já que o preço por vaso varia com a época do ano e a disponibilidade de plantas comerciais (CEASA, 2009; VEILLING, 2009).

A aplicação do $\mathrm{GA}_{3}$ na concentração de $125 \mathrm{mg} \mathrm{L}^{-1}$, em duas pulverizações foliares, apresentou a melhor resposta para a indução do florescimento em Phalaenopsis 'White 
Dream', aumentando a porcentagem de plantas floridas de 17 para $83 \%$ em condições ambientais desfavoráveis ao florescimento. Essa concentração também aumentou o comprimento das inflorescências, mantendo o número de flores por inflorescência e a qualidade da floração e das flores.

A indução do florescimento em Phalaenopsis 'White Dream' em condições ambientais não indutivas é possível pela aplicação via pulverização com o $\mathrm{GA}_{3}$. O uso desse regulador vegetal em concentrações adequadas melhora a qualidade da floração, pelo aumento no número de flores por inflorescência, sem alterar a qualidade da floração. Concentrações elevadas de $\mathrm{GA}_{3}$ prejudicam a qualidade da floração e das flores, causando alterações morfológicas indesejáveis para o comércio.

\section{AGRADECIMENTOS}

Aos Profs. Drs. Elizabeth Orika Ono, João Domingos Rodrigues, Norberto Silva, Carmen Boaro e Armando Tavares, pelas contribuições com o trabalho. À Fundação Shunji Nishimura de Tecnologia, pelo financiamento e apoio estrutural para a realização do trabalho.

\section{REFERÊNCIAS}

BLÁSQUEZ, M.A. et al. Gibberellins promote flowering of Arabidopsis by activating the LEAFY promoter. The Plant Cell, v.10, p.791-800, 1998.

CARDOSO, J.C.; CROCOMO, W.B.; RAETANO, C.G. Pragas das orquídeas: identificação, controle e manejo. Pompéia: Bless Gráfica e Editora, 2005. 140p.

CEASA. Cotação do Mercado Permanente de Flores do CEASA-Campinas. Disponível em: http://www. ceasacampinas.com.br/cotacoes/documentos/cotacao flores_completa.pdf. Acessado em Outubro de 2012.

CHEN, W.S. et al. Gibberellin and temperature influence carbohydrate content and flowering in Phalaenopsis. Physiologia Plantarum, Copenhagen, v.90, p.391-395, 1994.

CHEN, W.S. et al. Gibberellic acid and cytokinin affect Phalaenopsis flower morphology at high temperature. Hortscience, v.32, p.1069-1073, 1997.

CHEN, J. et al. Gibberellic Acid affects growth and flowering of Philodendron 'Black Cardinal'. Plant Growth Regulation, v.41, p.1-6, 2003.
CID, L.P.B. Introdução aos hormônios vegetais. Brasília: EMBRAPA- Recursos Genéticos e Biotecnologia. 2000. $180 \mathrm{p}$.

DAVIES, P.J. Plant hormones: Physiology, Biochemistry and Molecular Biology. $2^{\mathrm{a}}$ Edition, Kluwer Academic Publishers. 1995. 833p.

JUNQUEIRA, A.H.; PEETZ, M.S. 2010. Análise conjuntural do comércio exterior da floricultura brasileira. Revista Brasileira de Horticultura Ornamental, Campinas, v.16, n.1, p.79-81, 2010.

KARAGÜZEL, O. et al. The effects of $\mathrm{GA}_{3}$ and additional $\mathrm{KNO}_{3}$ fertilisation on flowering and quality characteristics of Gladiolus grandiflorus 'Eurovision'. In Anaç, D.; Martin-Prével, P. Improved crop quality by nutrient management. Netherlands: Kluwer Academic Publishers. 1999.

KATAOKA, K. et al. Changes in sugar content of Phalaeenopsis leaves before floral transition. Scientia Horticulturae, v.102, p.121-132, 2004.

KERBAUY, G.B. Fisiologia Vetetal. $2^{\mathrm{a}}$ edição expandida, revisada e atualizada. Rio de Janeiro, Ed. Guanabara Koogan Ltda. 2008. 431p.

KOZLOWSKA, et al. Changes in carbohydrate contents of Zantedeschia leaves under gibberellin-stimulated flowering. Acta Physiologiae Plantarum, v.29, p.27-32, 2007.

MUTASA-GÖTTGENS, E.; HEDDEN, P. Gibberelin as a factor in floral regulatory networks. Journal of Experimental Botany, v.60, p.1979-1989, 2009.

SIMÃO, S. Tratado de fruticultura. Piracicaba: FEALQ. 1998. 760p.

TAIZ, L.; ZEIGER, E. Fisiologia Vegetal. $4^{\mathrm{a}}$ Ed., Porto Alegre: Editora Artmed. 2008. 719p.

VEILLING. 2009. Critério de classificação: Phalaenopsis. Disponível em http://www.veiling.com.br/qualidade. swf?fileName=Phalaenopsis $\% 20$ Vaso.swf. Acessado em Setembro de 2012.

WANG, Y.T. Phalaenopsis orchid light requirement during the induction of spiking. Hortscience, v.30, p.59-61, 1995. 

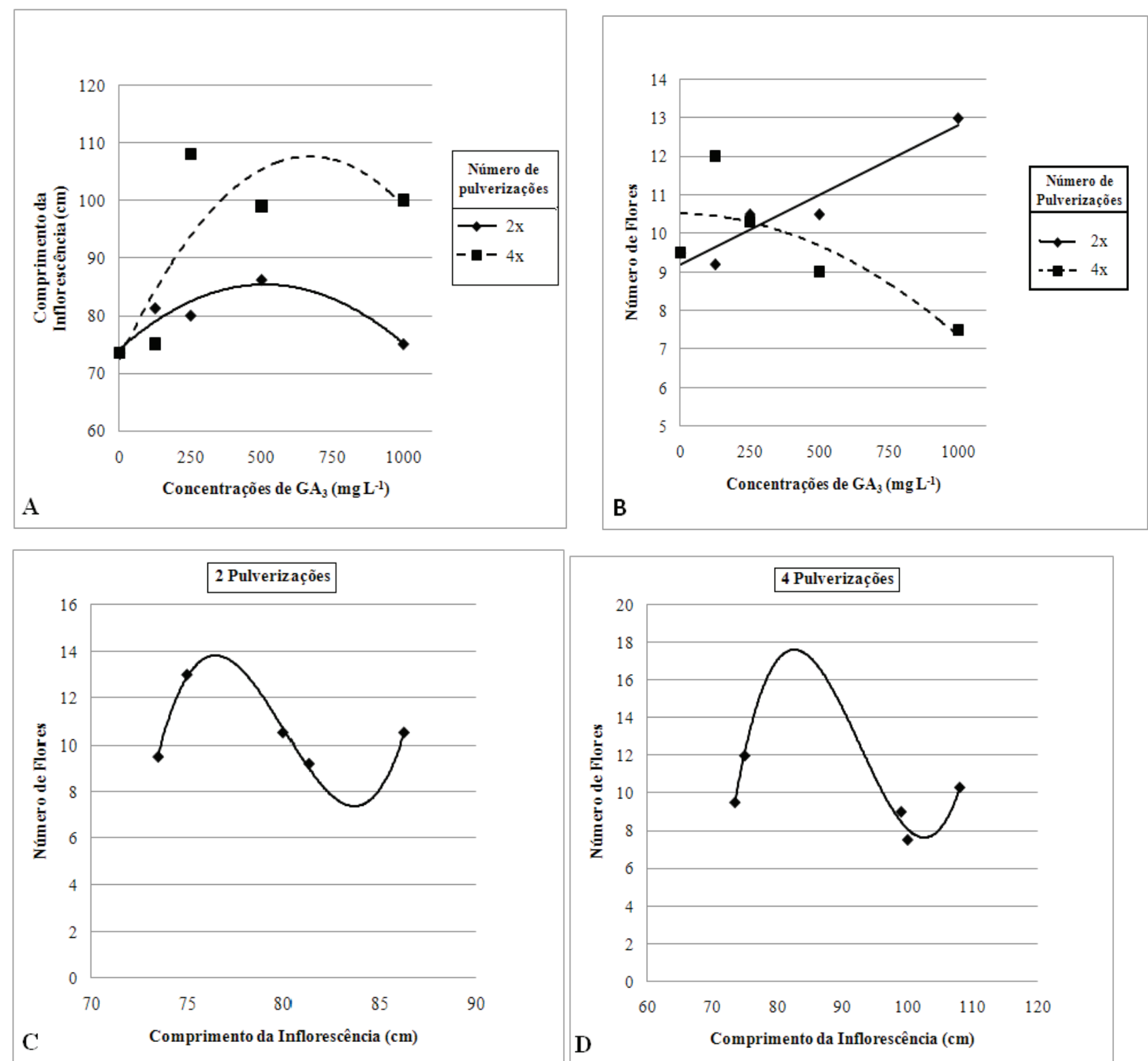

Figura 1. Correlações entre concentrações de Ácido Giberélico $\left(\mathrm{GA}_{3}\right) \mathrm{em} \mathrm{mg} \mathrm{L}^{-1}$, número de flores por planta e comprimento da inflorescência (cm) em orquídeas Phalaenopsis 'White Dream'.

A. Correlações entre concentrações de $\mathrm{GA}_{3}$ e o comprimento das inflorescências, $\mathrm{y}(2 \mathrm{x})=-4 * 10^{-4} \mathrm{x}^{2}+0,044 \mathrm{x}+74,107$,

$$
\begin{gathered}
\mathrm{R}^{2}=0,8797^{* *} \text { e y }(4 \mathrm{x})=-8^{*} 10^{-4} \mathrm{x}^{2}+0,105 \mathrm{x}+72,577 \\
\mathrm{R}^{2}=0,6674^{*}
\end{gathered}
$$

B. Correlações entre concentrações de $\mathrm{GA}_{3}$ e o número de flores, $\mathrm{y}(2 \mathrm{x})=0,0036 \mathrm{x}+9,183, \mathrm{R}^{2}=0,917 * *$ e y $(4 \mathrm{x})=$

$$
-3 * 10^{-5} x^{2}-0,0002 x+10,52, R^{2}=0,6432 * \text {; }
$$

$\mathrm{C}$ e D. Correlações entre o comprimento das inflorescências e o número de flores obtidas de plantas submetidas a duas e quatro de pulverizações, $y(2 x)=0,0349 x^{3}-8,3912 x^{2}+670,57 x-17816, R^{2}=0,9898 * *$ e y $(4 x)=0,0025 x^{3}-0,6996 x^{2}$ $+64,023 \mathrm{x}-1916,9, \mathrm{R}^{2}=0,9422 * * * \mathrm{e}^{* *}$ (significativo a 5 e $1 \%$ de probabilidade, respectivamente).

Figure 1. Correlations among concentrations of gibberellic acid (GA3) in $\mathrm{mg} L-1$ with number of flowers per plant and inflorescence length $(\mathrm{cm})$ in Phalaenopsis 'White Dream'. 
Tabela 1. Porcentagem de florescimento de plantas de Phalaenopsis 'White Dream' em diferentes concentrações e $\mathrm{n}^{\circ}$ de pulverizações de GA3 aplicadas via pulverização foliar

Table 1. Percentage of flowering in Phalaenopsis 'White Dream' under different concentrations and number of spraying of GA3 applied via foliar spray Pompéia, Maio de 2007

\begin{tabular}{cccccccc} 
Pulverizações & \multicolumn{9}{c}{ Florescimento $(\mathbf{\%})$} & & CV (\%) \\
& $\mathbf{0}$ & $\mathbf{1 2 5}$ & $\mathbf{2 5 0}$ & $\mathbf{5 0 0}$ & $\mathbf{1 . 0 0 0}$ & \\
\hline $2 \mathrm{x}$ & $17 \mathrm{~b}$ & $83 \mathrm{a}$ & $33 \mathrm{ab}$ & $50 \mathrm{ab}$ & $33 \mathrm{ab}$ & 53,52 \\
\hline $\mathrm{x}$ & 17 & 50 & 50 & 33 & 50 & 42,70 \\
\hline
\end{tabular}

Tabela 2. Diâmetro de flores e pétalas em diferentes concentrações e número de pulverizações, duas $(2 x)$ e quatro pulverizações (4x), de GA3 em plantas de Phalaenopsis 'White Dream'

Table 2. Flower diameter and petal width in Phalaenopsis 'White Dream' under different concentrations and number of spraying, two (2x) and four (4x) foliar spraying

\begin{tabular}{|c|c|c|c|c|c|c|}
\hline \multirow[t]{2}{*}{$\begin{array}{c}\text { Concentração } \\
\text { de } \mathrm{GA}_{3}(\mathrm{mg} \\
\left.\mathrm{L}^{-1}\right)\end{array}$} & \multicolumn{2}{|c|}{$\begin{array}{c}\text { Diâmetro } \\
\text { Flores }\end{array}$} & \multicolumn{2}{|c|}{$\begin{array}{c}\text { Diâmetro } \\
\text { Pétalas }\end{array}$} & \multicolumn{2}{|c|}{$\begin{array}{l}\text { Qualidade } \\
\text { Flores }\end{array}$} \\
\hline & $2 x$ & $4 x$ & $2 x$ & $4 x$ & $2 x$ & $4 x$ \\
\hline 0 & 10,25 & $10,25 \mathrm{~b}$ & $6,60 \mathrm{ab}$ & $6,60 \mathrm{~A}$ & $3 \mathrm{a}$ & $3 \mathrm{~A}$ \\
\hline 125 & 9,98 & $10,48 \mathrm{ab}$ & $6,28 \mathrm{~b}$ & $6,45 \mathrm{AB}$ & $3 \mathrm{a}$ & $3 \mathrm{~A}$ \\
\hline 250 & 9,94 & $11,00 \mathrm{ab}$ & $6,75 \mathrm{a}$ & $6,55 \mathrm{~A}$ & $3 \mathrm{a}$ & $1 \mathrm{~B}$ \\
\hline 500 & 9,80 & $11,19 \mathrm{a}$ & $6,65 \mathrm{a}$ & $6,68 \mathrm{AB}$ & $3 \mathrm{a}$ & $1 \mathrm{~B}$ \\
\hline 1.000 & 10,17 & $10,49 \mathrm{ab}$ & $6,63 \mathrm{ab}$ & $6,00 \mathrm{~B}$ & $2 \mathrm{~b}$ & $1 \mathrm{~B}$ \\
\hline CV (\%) & 2,43 & 2,64 & 2,75 & 4,45 & 15,97 & 37,27 \\
\hline
\end{tabular}

*Médias com letras iguais não diferem entre si pelo teste de Duncan em 5\% de probabilidade. 